\title{
A Review on Superalloys and IN718 Nickel-Based INCONEL Superalloy
}

Enes Akca

\author{
Department of Mechanical Engineering, Faculty of Engineering and \\ Natural Sciences, International University of Sarajevo, Hrasnicka cesta \\ 15, 71210, Sarajevo, Bosnia and Herzegovina \\ eakca@ius.edu.ba
}

\author{
Ali Gursel \\ Department of Mechanical Engineering, Faculty of Engineering and \\ Natural Sciences, International University of Sarajevo, Hrasnicka cesta \\ 15, 71210, Sarajevo, Bosnia and Herzegovina \\ Department of Mechanical Engineering, Faculty of Engineering, Duzce \\ University, Konuralp Yerleşkesi-Duzce, Turkey \\ agursel@ius.edu.ba
}

\begin{abstract}
In this study superalloys, their processing and application areas have been researched. The superalloys are widely used in the industrial production fields such as aircraft, nucleer, space industry and so on due to superior properties at high temperature and resistance to metallurgical and structural variations. The most important groups of the superalloys is Ni, Fe and Co-based superalloys. Also processing of the superalloys are investigated and another goal of the present paper is to investigate microstructure and mechanical properties of IN718 nickel-based inconel superalloy subjected to strengthening heat treatment.
\end{abstract}

Keywords: Superalloys, high temperature alloys, IN718 nickel-based superalloy.

\section{Introduction}

The origin of the term "Superalloy" is rather obscure. Early works refer only to "Heat Resisting Alloys" or "High Temperature Alloys." The nomenclature "Superalloy" did not surface until the late '40s when the very popular fictional character, Superman, became a television hero. From that day forward, the word "Super" became a popular descriptor in the vocabulary. It is interesting to speculate that a fictional hero, Superman, had a role in the identification of the extremely important materials known as Superalloys. It will be likely never known who exactly is responsible for the term Superalloy. Instead of discussing the nomenclature of the term, the meaning of the term "Superalloy" will be focused on explaining it.

Many scientists who have attempted to describe Superalloys often employ esoteric and limiting technical terminology in the definition. These definitions are too specific and are difficult to use and understand in general. Ironically, some currently used definitions exclude many useful alloys of the past and are not acceptable for future alloys like the intermetallic. New definitions are needed in order to understand completely. Simplistically, Superalloys are alloys which:
- are rich in at least one of the element nickel, cobalt and iron.

- maintain structural, surface and property stability; at elevated temperatures, under high stress, and in severe environment.

This definition accurately describes essentially all existing Superalloys and provides flexibility required to include new materials such as the titanium and aluminum. Under this specification, rather simple chrome cast irons can be classified as Superalloys. For many years, the chrome cast irons were successfully used as furnace grate and shaker hearth materials. Certainly this application requires alloys with "Super" properties in order to survive at high temperature under stress in the severe corrosive environment of burning coal. Furthermore, various cast irons are used even today as diesel engine turbocharger casings and exhaust manifolds which operate at temperatures up to about $1400{ }^{\circ} \mathrm{F}(760$ $\left.{ }^{\circ} \mathrm{C}\right)$. By adoption of the proposed definition we find that Superalloys have a much longer history of service and that the door is opened wide for the alloys of the future. 
Superalloys are heat-resisting alloys based on nickel, nickel-iron, or cobalt that exhibit a combination of mechanical strength and resistance to surface degradation [1]. In fact, it is primarily used in gas turbines, coal conversion plants, and chemical process industries, and for other specialized applications requiring heat and/or corrosion resistance. A noteworthy feature of nickel-base alloys is their use in load-bearing applications at temperatures in excess of $80 \%$ of their incipient melting temperatures, a fraction that is higher than for any other class of engineering alloys.

This paper will also describe the investigations of a nanostructured (NS) state of nickel based INCONEL alloy 718 (IN718). This structure was generated in bulk semi products by severe plastic deformation (SPD) via multiple isothermal forging (MIF) of a coarse-grained alloy. The initial structure consisted of $\gamma$-phase grains with disperse precipitations of $\gamma^{\prime}$ ' phase in the forms of discs, $50-75 \mathrm{~nm}$ in diameter and $20 \mathrm{~nm}$ in thickness.

\section{Classification of Superalloys}

Superalloys are classified into three based on the predominant metal present in the alloy. They are;

- Nickel-based superalloys

- Iron-based superalloys

- Cobalt-based superalloys

\subsection{Iron-based Superalloys}

Irons-base superalloys evolved from austenitic stainless steels and are based on the principle of combining a closed-packed FCC matrix with (in most cases) both solid-solution hardening and precipitateforming elements. The austenitic matrix is based on nickel and iron, with at least $25 \% \mathrm{Ni}$ needed to stabilize the FCC phase. Other alloying elements, such as chromium, partition primarily to the austenite for solidsolution hardening [2].

The iron-based superalloys, which are less expensive than cobalt or nickel-based superalloys, are of three types: alloys that can be strengthened by a martensitic type of transformation, alloys that are austenitic and are strengthened by a sequence of hot and cold working (usually, forging at 2,000 to $2,100^{\circ} \mathrm{F}$ followed by finishing at 1,200 to $1,600^{\circ} \mathrm{F}$ ), and austenitic alloys strengthened by precipitation hardening.Some metallurgists consider the last group only as superalloys, the others being categorized as high-temperature, high- strength alloys. In general, the martensitic types are used at temperatures below $1,000^{\circ} \mathrm{F}$; the austenitic types, above $1,000^{\circ} \mathrm{F}$.

The AISI 600 series of superalloys consists of six subclasses of iron-based alloys:

○ 601 through 604: Martensitic low-alloy steels.

- 610 through 613: Martensitic secondary hardening steels.

○ 614 through 619: Martensitic chromium steels.

○ 630 through 635: Semi-austenitic and martensitic precipitation-hardening stainless steels.

- 650 through 653: Austenitic steels strengthened by hot/cold work.

○ 660 through 665: Austenitic superalloys; all grades except alloy 661 are strengthened by second-phase precipitation.

Iron-based superalloys are characterized by high temperature as well as room-temperature strength and resistance to creep, oxidation, corrosion, and wear. Wear resistance increases with carbon content. Maximum wear resistance is obtained in alloys 611,612 , and 613 , which are used in high-temperature aircraft bearings and machinery parts subjected to sliding contact. Oxidation resistance increases with chromium content. The martensitic chromium steels, particularly alloy 616 , are used for steam-turbine blades.

The superalloys are available in all conventional mill forms; billet, bar, sheet, forgings, and special shapes are available for most alloys. In general, austenitic alloys are more difficult to machine than martensitic types, which machine best in the annealed condition. Austenitic alloys are usually "gummy" in the solution-treated condition and machine best after being partially aged or fully hardened.

Crack sensitivity makes most of the martensitic steels difficult to weld by conventional methods. These alloys should be annealed or tempered prior to welding; even then, pre-heating and post-heating are recommended. Welding drastically lowers the mechanical properties of alloys that depend on hot/cold work for strength. All of the martensitic low-alloy steels machine satisfactorily and are readily fabricated by hot working and cold working. The martensitic secondary-hardening and chromium alloys are all hot worked by pre-heating and hot forging. Austenitic alloys are more difficult to forge than the martensitic grades. 


\begin{tabular}{|c|c|c|c|c|c|c|c|c|c|c|c|c|c|c|c|}
\hline Alloy & $\mathrm{Cr}$ & Co & Mo & W & $\mathrm{Ta}$ & $\mathrm{Re}$ & $\mathrm{Nb}$ & $\mathrm{Al}$ & $\mathrm{Ti}$ & Hf & $\mathrm{C}$ & B & $\mathrm{Y}$ & $\mathrm{Zr}$ & Other \\
\hline \multicolumn{16}{|c|}{ Conventionally Cast Alloys } \\
\hline Mar-M246 & 8.3 & 10.0 & 0.7 & 10.0 & 3.0 & - & - & 5.5 & 1.0 & 1.50 & 0.14 & 0.02 & - & 0.05 & - \\
\hline Rene $^{\prime} 80$ & 14.0 & 9.5 & 4.0 & 4.0 & - & - & - & 3.0 & 5.0 & - & 0.17 & 0.02 & - & 0.03 & - \\
\hline IN-713LC & 12.0 & - & 4.5 & - & - & - & 2.0 & 5.9 & 0.6 & - & 0.05 & 0.01 & - & 0.10 & - \\
\hline $\mathrm{C} 1023$ & 15.5 & 10.0 & 8.5 & - & - & - & - & 4.2 & 3.6 & - & 0.16 & 0.01 & - & - & - \\
\hline \multicolumn{16}{|c|}{ Directionally Solidified Alloys } \\
\hline IN792 & 12.6 & 9.0 & 1.9 & 4.3 & 4.3 & - & - & 3.4 & 4.0 & 1.00 & 0.09 & 0.02 & - & 0.06 & - \\
\hline GTD111 & 14.0 & 9.5 & 1.5 & 3.8 & 2.8 & - & - & 3.0 & 4.9 & - & 0.10 & 0.01 & - & - & - \\
\hline \multicolumn{16}{|c|}{ First-Generation Single-Crystal Alloys } \\
\hline PWA 1480 & 10.0 & 5.0 & - & 4.0 & 12.0 & - & - & 5.0 & 1.5 & - & - & - & - & - & - \\
\hline Rene' $^{\prime}$ 4 & 9.8 & 7.5 & 1.5 & 6.0 & 4.8 & - & 0.5 & 4.2 & 3.5 & 0.15 & 0.05 & 0.00 & - & - & - \\
\hline CMSX-3 & 8.0 & 5.0 & 0.6 & 8.0 & 6.0 & - & - & 5.6 & 1.0 & 0.10 & - & - & - & - & - \\
\hline \multicolumn{16}{|c|}{ Second-Generation Single-Crystal Alloys } \\
\hline PWA 1484 & 5.0 & 10.0 & 2.0 & 6.0 & 9.0 & 3.0 & - & 5.6 & - & 0.10 & - & - & - & - & - \\
\hline Rene' N5 $^{\prime}$ & 7.0 & 7.5 & 1.5 & 5.0 & 6.5 & 3.0 & - & 6.2 & - & 0.15 & 0.05 & 0.00 & 0.01 & - & - \\
\hline CMSX-4 & 6.5 & 9.0 & 0.6 & 6.0 & 6.5 & 3.0 & - & 5.6 & 1.0 & 0.10 & - & - & - & - & - \\
\hline \multicolumn{16}{|c|}{ Third-Generation Single-Crystal Alloys } \\
\hline Rene' N6 & 4.2 & 12.5 & 1.4 & 6.0 & 7.2 & 5.4 & - & 5.8 & - & 0.15 & 0.05 & 0.00 & 0.01 & - & - \\
\hline CMSX-10 & 2.0 & 3.0 & 0.4 & 5.0 & 8.0 & 6.0 & 0.1 & 5.7 & 0.2 & 0.03 & - & - & - & - & - \\
\hline \multicolumn{16}{|c|}{ Wrought Superalloys } \\
\hline IN 718 & 19.0 & - & 3.0 & - & - & - & 5.1 & 0.5 & 0.9 & - & - & 0.02 & - & - & $18.5 \mathrm{Fe}$ \\
\hline Rene' $^{\prime} 41$ & 19.0 & 11.0 & 10.0 & - & - & - & - & 1.5 & 3.1 & - & 0.09 & 0.005 & - & - & - \\
\hline Nimonic $80 \mathrm{~A}$ & 19.5 & - & - & - & - & - & - & 1.4 & 2.4 & - & 0.06 & 0.003 & - & 0.06 & - \\
\hline Waspaloy & 19.5 & 13.5 & 4.3 & - & - & - & - & 1.3 & 3.0 & - & 0.08 & 0.006 & - & - & - \\
\hline Udimet 720 & 17.9 & 14.7 & 3.0 & 1.3 & - & - & - & 2.5 & 5.0 & - & 0.03 & 0.03 & - & 0.03 & - \\
\hline \multicolumn{16}{|c|}{ Powder-Processed Superalloys } \\
\hline Rene' 95 & 13.0 & 8.0 & 3.5 & 3.5 & - & - & 3.5 & 3.5 & 2.5 & - & 0.065 & 0.013 & - & 0.05 & - \\
\hline Rene' $^{\prime} 88$ DT & 16.0 & 13.0 & 4.0 & 4.0 & - & - & 0.7 & 2.1 & 3.7 & - & 0.03 & 0.015 & - & - & - \\
\hline N18 & 11.2 & 15.6 & 6.5 & - & - & - & - & 4.4 & 4.4 & 0.5 & 0.02 & 0.015 & - & 0.03 & - \\
\hline IN100 & 12.4 & 18.4 & 3.2 & - & - & - & - & 4.9 & 4.3 & - & 0.07 & 0.02 & & 0.07 & \\
\hline
\end{tabular}

Table 1: Compositions of commercial Ni-based superalloys (wt. \%, bal. Ni).

\subsection{Nickel-based Superalloys}

Nickel-base superalloys are the most complex, the most widely used for the hottest parts, and, for many metallurgists, the most interesting of all superalloys [3]. They currently constitute over $50 \%$ of the weight of advanced aircraft engines. The principal characteristics of nickel as an alloy base are the high phase stability of FCC nickel matrix and the capability to be strengthened by a variety of direct and indirect means. Further, the surface stability of nickel is readily improved by alloying with chromium and/or aluminum [4].

The most prominent use is in the manufacture of gas turbines for use in commercial and military aircraft, power generation, and marine propulsion. Superalloys also find important applications in the oil and gas industry, space vehicles, submarines, nuclear reactors, military electric motors, chemical processing vessels, and heat exchanger tubing [5]. Several generations of superalloys have been developed, each generation tending to have higher temperature resistance [6]. The latest generations of superalloys incorporate expensive alloying metals such as rhenium and ruthenium to achieve the desired characteristics.

Because of this, the cost of some new super alloys can be five times more expensive than high-quality turbine steel. The outlook is for considerable growth in usage in these areas, in particular as the aircraft manufacturing and electrical power generation industries grow. However, the high cost of some of the alloying metals used along with nickel in superalloys may be a constraint to usage. For example, rhenium currently (March 2013) trades at about $\$ 4200$ per kilogram and ruthenium at $\$ 65$ to 85 per ounce.

A listing of some of nickel-based superalloys, with information on their composition and some of the uses is provided here:

- Inconel Alloy $600(76 \mathrm{Ni}-15 \mathrm{Cr}-8 \mathrm{Fe})$ is a standard material of construction for nuclear reactors, also used in the chemical industry in heaters, stills, evaporator tubes and condensers,

- Nimonic alloy 75 (80/20 nickel-chromium alloy with additions of titanium and carbon) used in gas turbine engineering, furnace components and heat-treatment equipment,

○ Alloy 601. Lower nickel (61\%) content with aluminium and silicon additions for improved oxidation and nitriding resistance chemical processing, pollution control, aerospace, and power generation, 
○ Alloy X750. Aluminium and titanium additions for age hardening. Used in gas turbines, rocket engines, nuclear reactors, pressure vessels, tooling, and aircraft structures,

○ Alloy 718. (55Ni-21Cr-5Nb-3Mo). Niobium addition to overcome cracking problems during welding. Used in aircraft and land-based gas turbine engines and cryogenic tankage,

$\circ$ Alloy X (48Ni-22Cr-18Fe-9Mo + W). Hightemperature flat-rolled product for aerospace applications,

○ Waspaloy (60Ni-19Cr-4Mo-3Ti-1.3Al). Proprietary alloy for jet engine applications,

- ATI 718Plus. A lower cost alloy which exceeds the operating temperature capability of standard 718 alloy by $100 \mathrm{~F}^{\mathrm{o}}\left(55 \mathrm{C}^{\mathrm{o}}\right)$ allowing engine manufacturers to improve fuel efficiency,

- Nimonic 90. (Ni 54\% min Cr $18-21 \%$ Co $15-21 \%$ Ti 2-3\% Al 1-2\%) used for turbine blades, discs, forgings, ring sections and hot-working tools,

○ Rene' N6. (4Cr-12Co-1Mo-W6 -Ta7- Al5.8 - Hf 0.2 Re5- BalNi) 3rd generation single crystal alloy used in jet engines,

○ TMS 162 (3Cr- 6Co-4Mo-6W-6Ta-6Al-5Re-6Rubalance $\mathrm{Ni}$ ) 5 th generation single crystal alloy for turbine blades.

\subsection{Cobalt-based Superalloys}

Nickel-based superalloys have limitations at very high temperatures, and so components in the combustion chamber, where the temperature may reach as high as $1100^{\circ} \mathrm{C}$, are usually made of cobalt-based alloys.

The cobalt-based superalloys (Table 2) are not as strong as nickel-based superalloys, but they retain their strength up to higher temperatures. They derive their strength largely from a distribution of refractory metal carbides (combinations of carbon and metals such as Mo and W), which tend to collect at grain boundaries (Figure 1). This network of carbides strengthens grain boundaries and alloy becomes stable nearly up to the melting point. In addition to refractory metals and metal carbides, cobalt superalloys generally contain high levels of $\mathrm{Cr}$ to make them more resistant to corrosion that normally takes place in the presence of hot exhaust gases. The $\mathrm{Cr}$ atoms react with oxygen atoms to form a protective layer of $\mathrm{Cr}_{2} \mathrm{O}_{3}$ which protects the alloy from corrosive gases. Being not as hard as nickel-based superalloys cobalt superalloys are not so sensitive to cracking under thermal shocks as other superalloys. Co-based superalloys are therefore more suitable for parts that need to be worked or welded, such as those in the intricate structures of the combustion chamber.

\begin{tabular}{|c|c|c|c|c|c|c|c|c|c|}
\hline Alloy & $\mathrm{C}$ & $\mathrm{Mn}$ & $\mathrm{Si}$ & $\mathrm{Cr}$ & $\mathrm{Ni}$ & $\mathrm{Mo}$ & $\mathrm{W}$ & $\mathrm{Fe}$ & $\mathrm{Co}$ \\
\hline $\mathrm{X}-45$ & 0.25 & .5 & 0.9 & 25 & 10 & - & 7.5 & $<2$ & Bal. \\
\hline X-40 & 0.5 & .5 & 0.9 & 25 & 10 & - & 7.5 & $<2$ & Bal. \\
\hline FSX-414 & 0.35 & .5 & 0.9 & 29.5 & 10 & - & 7.5 & $<2$ & Bal. \\
\hline WI-52 & 0.45 & .4 & 0.4 & 21 & - & - & 11 & 2 & Bal. \\
\hline Haynes -25 & 0.1 & 1.2 & 0.8 & 20 & 10 & - & 15 & $<3$ & Bal. \\
\hline F-75 & 0.25 & .5 & 0.8 & 28 & $<1$ & 6 & $<.2$ & $<0.75$ & Bal. \\
\hline $\begin{array}{c}\text { Haynes } \\
\text { Ultimet }\end{array}$ & 0.06 & .8 & 0.3 & 25 & 9 & 5 & 2 & 3 & Bal. \\
\hline Co 6 & 1.1 & & 0.8 & 29 & $<3$ & $<1.5$ & 5.5 & $<3$ & Bal. \\
\hline
\end{tabular}

Table 2: Chemical Composition of Some Cobalt-Based Superalloys.
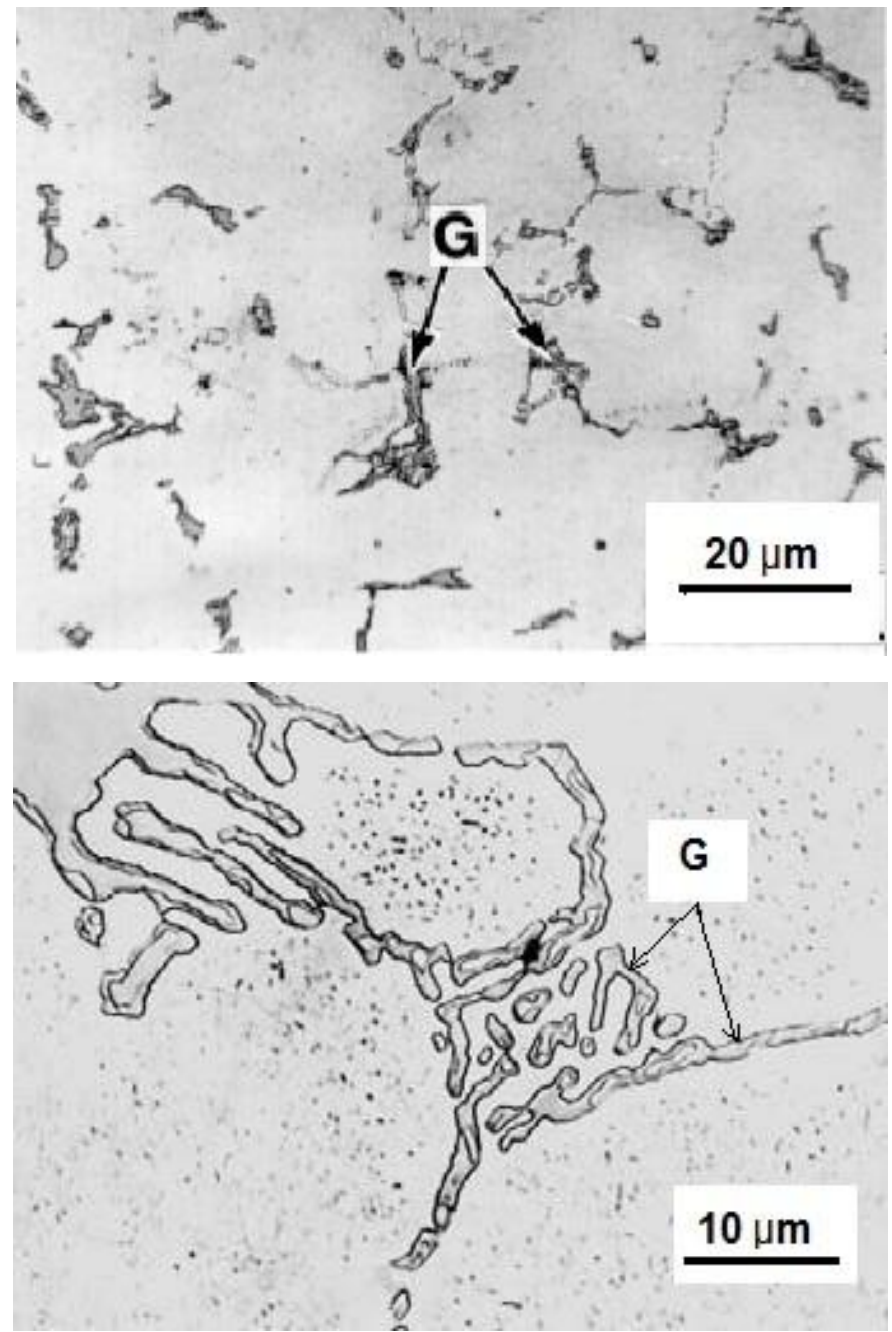

Figure 1: Optical micrograph of Haynes-25. G-mainly M6C carbides.

\section{Application of Superalloys}

The high-temperature applications of superalloys are extensive, including components for aircraft, chemical plant equipment, and petrochemical equipment $[7,8]$.

Besides that superalloys are widely used in Aerospace and Marine industries, Nuclear reactors, heat 
exchanger tubing, and industrial gas turbines. Figure 2 shows the F119 engine, which is the latest in a series of military engines to power high-performance aircraft. The gas temperatures in these engines in the hot sections (rear areas of the engine) may rise to levels far above $2000^{\circ} \mathrm{F}$ $\left(1093^{\circ} \mathrm{C}\right)$. Cooling techniques reduce the actual component metal temperatures to lower levels, and superalloys that can operate at these temperatures are the major components of the hot sections of such engines [9].

The significance of superalloys in today's commerce is typified by the fact that, whereas in 1950 only about $10 \%$ of the total weight of an aircraft gas turbine engine was made of superalloys, by 1985 this figure had risen to about 50\%. Table 3 lists some current applications of superalloys. It will be noted, however, that not all applications require elevated-temperature strength capability. Their high strength coupled with corrosion resistance has made certain superalloys standard materials for biomedical devices. Superalloys also find use in cryogenic applications.

Applications of superalloys are categorized below; the bulk of tonnage is used in gas turbines:

- Aircraft gas turbines: disks, combustion chambers, bolts, casings, shafts, exhaust systems, cases, blades, vanes, burner cans, afterburners, thrust reversers

- Steam turbine power plants: bolts, blades, stack gas re-heaters

- Reciprocating engines: turbochargers, exhaust valves, hot plugs, valve seat inserts

- Metal processing: hot-work tools and dies, casting dies

- Medical applications: dentistry uses, prosthetic devices

○ Space vehicles: aerodynamically heated skins, rocket engine parts

- Heat-treating equipment: trays, fixtures, conveyor belts, baskets, fans, furnace mufflers

- Nuclear power systems: control rod drive mechanisms, valve stems, springs, ducting

- Chemical and petrochemical industries: bolts, fans, valves, reaction vessels, piping, pumps

- Pollution control equipment: scrubbers

- Metals processing mills: ovens, afterburners, exhaust fans

- Coal gasification and liquefaction systems: heat exchangers, re-heaters, piping.

\subsection{Aero and land turbines}

Cobalt superalloys are well-suited to high temperature creep and fatigue resistant non-rotating applications where stress levels are lower than for rotating components. For this reason, turbine vanes and other static non-rotating components are frequently designed in cobalt alloys [10]. A somewhat lower coefficient of thermal expansion and better thermal conductivity than the nickel superalloys make cobalt alloys good candidates for applications where thermal fatigue is a critical design issue. Due to long service life requirements, land based casting specifications are becoming progressively more stringent (more rigorous than for similar aero counterparts in some cases).

\subsection{Surgical implants}

The alloy under the proprietary name Vitallium has been known since the ' 30 's of the last century. Today, this alloy is used for orthopaedic implants, most notably as artificial hips and knees. The alloy is generically referred to by its ASTM designation F-75 and contains $29 \% \mathrm{Cr}$ and $6 \%$ Mo. While the ASTM specification limits carbon to $0.35 \%$, implant manufacturers have opted for lower levels of carbon and an intentional alloying with nitrogen. This addition of nitrogen has allowed Co-Cr-Mo alloy to achieve high levels of strength with good ductility and without sacrificing corrosion resistance and bio-compatibility. Co-Cr-Mo implants may be produced by casting, forging or powder metallurgy technology.

\subsection{Gas Turbine Engines}

Superalloys are commonly used in gas turbine engines in those areas of the engine that are subject to high temperatures and which require high strength, excellent creep resistance, as well as corrosion and oxidation resistance. In turbine engines this is in the high pressure turbine where blades can face temperatures approaching if not beyond their melting temperature $[11,5]$. New jet engines are more efficient because of higher operating temperatures, requiring higherperforming components. The use of super alloys can allow the operating temperature to be increased from $1200^{\circ} \mathrm{F}$ to $1300^{\circ} \mathrm{F}$. Besides increasing efficiency and power output, higher temperatures result in reduced emissions because the combustion cycle is more complete [12,13]. The diagram below shows the areas within a jet engine where nickel-based super alloys are used i.e. the hottest, highest pressure zones. 


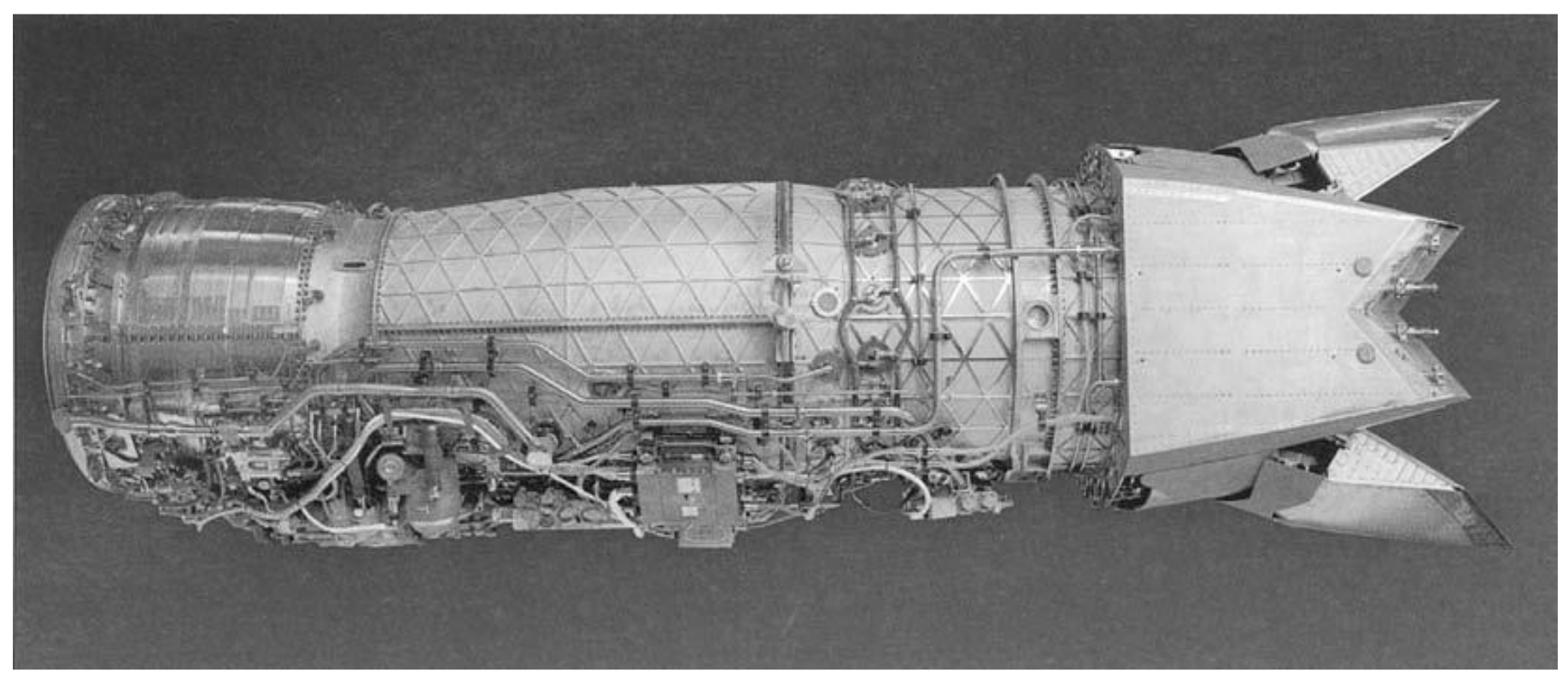

Figure 2: F119 gas turbine engine; a major user of superalloys.

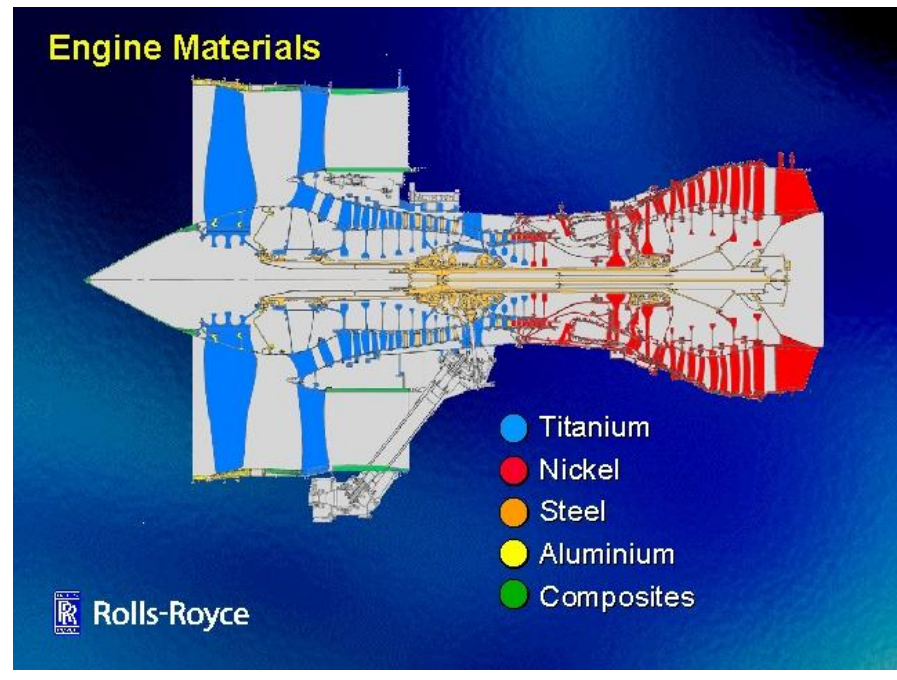

Figure 3:commonly used materials in gas turbine engine components.

\subsection{Oil and Gas industry}

Nickel-based superalloys are increasingly finding applications in the oil and gas sector. The environments encountered in oil and natural gas production are frequently corrosive and challenging. Often significant levels of hydrogen sulfide, carbon dioxide, chlorides, and free sulfur are present. In some of these environments high pressure and temperatures up to $450^{\circ} \mathrm{F}\left(232^{\circ} \mathrm{C}\right)$ can be encountered. Processing of oil and natural gas under these environmental conditions requires special materials. Nickel-base alloys 718,725 , and 925 are commonly used in oil and natural gas production. These alloys contain chrome and molybdenum which aid in resisting corrosion. Alloy 718 was initially developed for use in aerospace and gas turbines, but has become the preferred material for the manufacture of wellhead components, auxiliary and down-hole tools, and subsurface safety valves [14].

\section{Processing of Superalloys}

Superalloy processing begins with the fabrication of large ingots that are subsequently used for one of three major processing routes: 1) remelting and subsequent investment casting, 2) remelting followed by wrought processing, or 3) remelting to form superalloy powder that is subsequently consolidated and subjected to wrought processing operations [9]. Ingots are fabricated by vacuum induction melting (VIM) in a refractory crucible to consolidate elemental and/or revert materials to form a base alloy. Although selected alloys can potentially be melted in air/slag environments using electric arc furnaces, VIM melting of superalloys is much more effective in the removal of low-melting-point trace contaminants. Following the vaporization of the contaminants, the carbon boil reaction is used to deoxidize the melt before the addition of the reactive forming elements such as $\mathrm{Ti}, \mathrm{Al}$, and Hf. Once the desired alloy composition of the VIM ingot is attained, the solidified ingot is then subsequently subjected to additional melting or consolidation processes that are dependent upon the final application of the material. Charge weights of VIM ingots may range from $\sim 2500 \mathrm{~kg}$ to in excess of 27,500 kg [15].

Considering the stringent requirements for minimizing defects in gas industry and turbines etc, a detailed understanding of structure evolution in each of these processing paths is essential. In the following sections, we briefly review the processing approaches 
and aspects of superalloy structure that influence properties of superalloys [16].

\subsection{Cast Superalloys}

Investment casting is the primary casting process for fabrication of superalloy components with complex shapes, including blades and vanes. Ceramic molds containing alumina, silica, and/or zirconia are utilized in this process (Figure 4). The molds are fabricated by progressive buildup of ceramic layers around a wax pattern of the cast component. Ceramic cores can be embedded in the wax to obtain complex internal cooling structures. A thermal cycle removes the wax, and the mold is filled with remelted superalloy in a preheated vacuum chamber to obtain a shaped casting. The singleuse mold is removed once the alloy has cooled to room temperature. Castings may be equiaxed, columnar grained, or single crystal. Equiaxed castings solidify fairly uniformly throughout their volume, whereas columnar and single-crystal castings are withdrawn from a hot zone in the furnace to a cold zone at a controlled rate. Following initial solidification, castings are subjected to a series of subsequent heat-treatment cycles that serve to reduce segregation, establish one or more size populations of $\gamma^{\prime}$ precipitates, modify the structure of grain boundary phases (particularly carbides), and/or assist in the application of coatings.

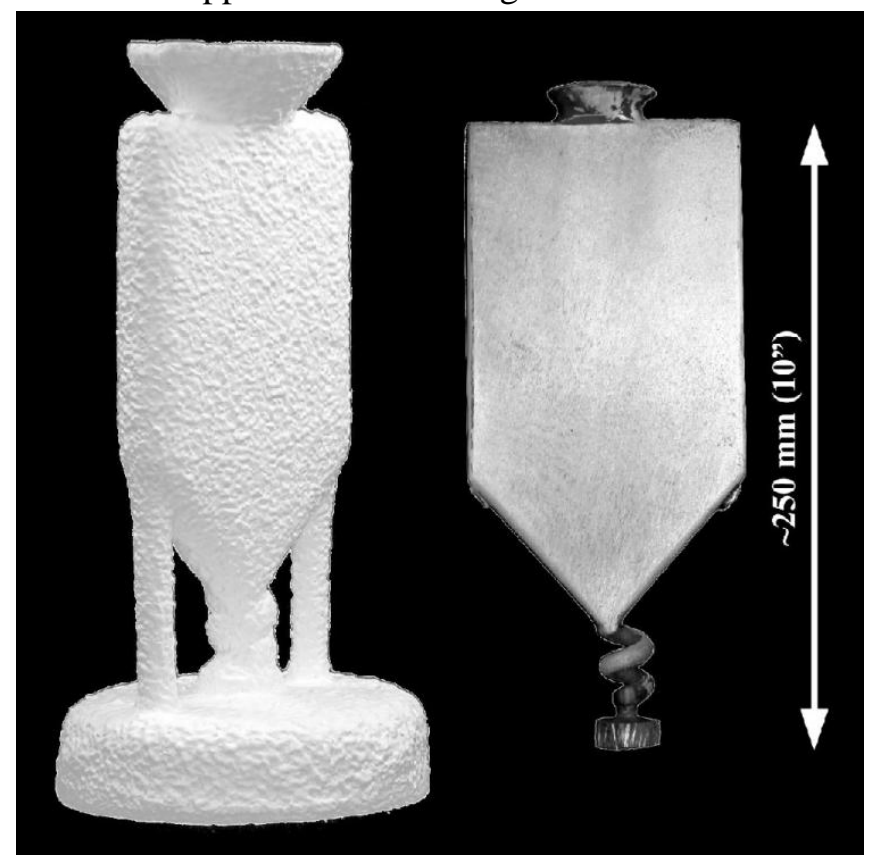

Figure 4: Ceramic investment casting mold with singlecrystal starter at the bottom of the plate and singlecrystal plate following directional solidification and removal of ceramic mold (courtesy of A. J. Elliott).

In all casting processes, the final structure (and therefore properties) of the material are sensitive to the thermal conditions present during solidification of the casting. Solidification is dendritic in character, and the primary and secondary dendrite arm spacings are dependent on cooling rate, $G * R$ (Figure 5). Associated with the dendritic solidification is segregation of the constituent alloying elements.
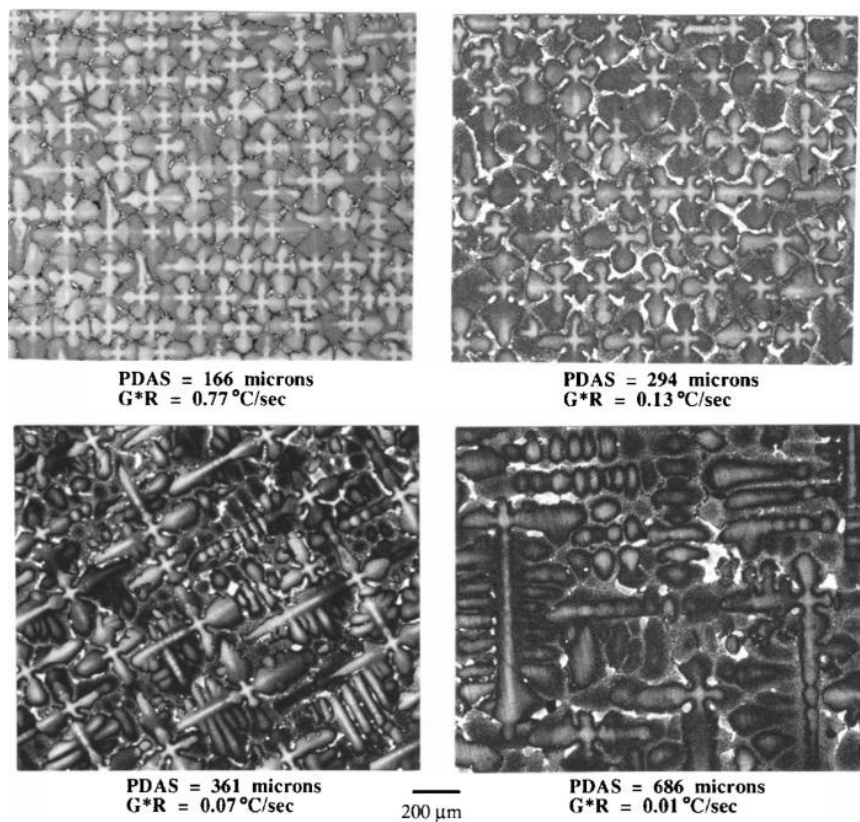

Figure 5: Variation in dendrite morphology and primary dendrite arm spacing (PDAS) with cooling rate $\left(G^{*} R\right)$ during solidification.

\subsection{Wrought Superalloys}

As mentioned previously, wrought alloys are typically fabricated by remelting of VIM ingots to form a secondary ingot or powder for subsequent deformation processing. A secondary melting process is necessary for wrought alloys because the high-temperature structural properties of Ni-based superalloys are very sensitive to microstructural variations, chemical in homogeneities, and inclusions. As ingot sizes increase, VIM melting often results in macro segregation or the formation of large shrinkage cavities during solidification. The formation of these solidification defects is caused by large-scale solute segregation associated with dendritic solidification under low thermal gradients. Because heat transfer during solidification of VIM ingots is limited by the low intrinsic thermal conductivity of the solidifying mass, large ingots are very prone to the formation of these features. Thus other secondary melting processes are utilized, including vacuum arc remelting (VAR), electro-slag remelting (ESR), and electron beam cold hearth refining (EBCHR) [17]. Here, only the more common VAR process is discussed in the context of avoiding property-reducing defects. 


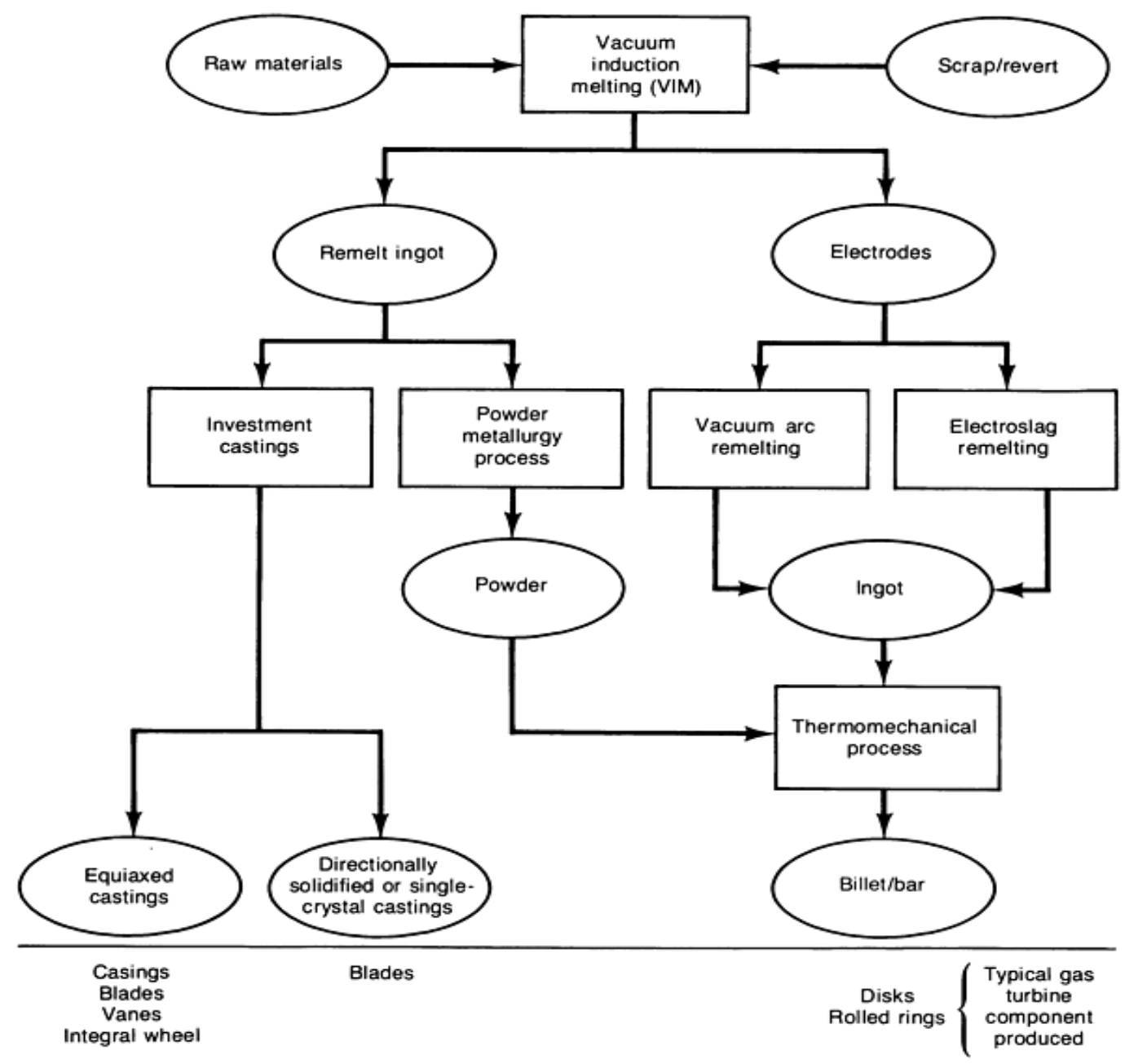

Figure 6: Flow diagram of processes widely used to produce superalloy component.

\subsubsection{Melting and Consolidation of Wrought Alloys}

Superalloy ingots must be melted and cast with due regard for the volatility and reactivity of the elements present. Vacuum melting processes are a necessity for many nickel- and iron-nickel-base alloys because of the presence of aluminum and titanium as solutes. Cobaltbase alloys, on the other hand, do not usually contain these elements and, therefore, may be melted in air.

\subsubsection{Melt Processes}

The traditional processes used to produce superalloy components are identified in Figure 6.

The VIM process produces liquid metal under vacuum in an induction-heated crucible. It is used as a primary melting step in the route to producing wrought and cast products, as well as near-net shape. Before being melted, the raw material can be refined and purified and its composition can be controlled. Vacuum induction melting has been widely used in the manufacture of superalloys, which must be melted under vacuum or in an inert gas atmosphere because of their reactivity with atmospheric oxygen and nitrogen.

The VAR process, a secondary melting technique, converts VIM-processed electrodes into ingots whose chemical and physical homogeneity have been significantly improved. In this process, a stub is welded to one end of an electrode, which is then suspended over a water-cooled copper crucible. Next, an arc is struck between the end of the electrode and the crucible bottom. Maintaining the arc generates the heat required to melt the electrode, which drips into the crucible and can subsequently be poured into molds. Many inclusions can be removed by flotation or a chemical and physical processes before the molten material solidifies.

The ESR process, another secondary melting technique, may appear to be similar to the VAR process, but there are a number of differences. Remelting does not occur by striking an arc under vacuum. Instead, an ingot is built up in a water cooled mold by melting a consumable electrode that is immersed in a slag, which is superheated by means of resistance heating. Rather than 
operating in a vacuum, the process is conducted in air under the molten slag. During melting, metal droplets fall through the molten slag, and chemical reactions reduce sulfur and nonmetallic inclusions. Both ESR and VAR processes allow directional solidification of an ingot from bottom to top, yielding high density and homogeneity in its macrostructure, as well as an absence of segregation and shrinkage cavities.

\subsection{Powder Metallurgy Superalloys}

To increase the strength of polycrystalline $\mathrm{Ni}$ based superalloys, levels of refractory alloying additions and $\gamma$ '-forming elements have gradually increased to levels that make conventional processing routes deficient [18]. Elements such as W, Mo, Ti, Ta, and Nb effectively strengthen the alloy but also result in severe segregation within the ingot upon solidification. Additionally, the limited ductility of the high-strength alloys renders the ingot susceptible to cracking as thermally induced stresses evolve during cooling. Powder-processing routes have been developed to overcome the difficulties associated with melt-related defects and are viable for the production of advanced high-strength polycrystalline superalloy components. Listed in Table 1 are the compositions of some commercially available powderprocessed Ni-based superalloys [19].

Powder processing begins with gas or vacuum atomization of a highly alloyed VIM ingot. Rapid solidification of the fine powders effectively suppresses macro segregation within the alloy. Because the low ductility associated with the corresponding high strength causes many of these advanced superalloys to be very sensitive to initial flaw sizes, the atomized powders are separated based on particle size. Standard 150 or 270 meshes are used to separate the powders into sizes $>100 \mu$ mand $>50 \mu \mathrm{m}$ respectively. Powder sizes directly influence the initial potential crack size present in the finished component. Although finer powder sizes are desired to minimize initial defect sizes, costs increase substantially as yields are substantially reduced.

Once powders are collected into steel cans, the cans are evacuated under vacuum and sealed. The cans are then hot isostatically pressed (HIP) or extruded to consolidate the powder. The HIP process consists of heating the alloy to just below the $\gamma$ 'solvus temperature under a hydrostatic pressure of up to $310 \mathrm{MPa}$. After 4 to $5 \mathrm{~h}$, diffusion bonding and sintering of the powders under pressure yields a fully dense superalloy billet. Billet sizes are limited by the capacity of the HIP furnace; however, systems capable of forming billets up to $150 \mathrm{~cm}$ in diameter and $300 \mathrm{~cm}$ in height are available. Consolidation under hot extrusion is often preferred over HIP because of the ability to produce fine-grained structures (ASTM 12) and reduce effects associated with prior particle boundaries. The evacuated can containing the superalloy powder is hot extruded through a set of dies that greatly reduces the diameter. During this thermomechanical process, the individual powder particles are subjected to deformation and any oxide films initially present on the surfaces of the powder are broken up. Because substantial plastic deformation and adiabatic heating occurs during this process, hot extrusion temperatures are selected such that temperatures are maintained below the $\gamma^{\prime}$ solvus temperature.

\section{Investigation of IN718 Superalloy}

Inconel 718 (IN718) is the most frequently used nickel based superalloys; hence this paper is also focused on an investigation into the microstructureand mechanical properties Inconel 718. Some of the applications of nickel based superalloys are in aircraft gas turbines (eg. disks, combustion chamber, casings, shafts, exhaust system, blades, vanes, burner, cans, stack gas reheaters), reciprocating engines (eg. turbochargers, exhaust valves hot plugs, valve seat inserts), metal processing (eg. hot work tools and dies), space vehicles (eg. Aerodynamically heated skins, rocket engine parts) heat treating equipments (eg. trays, fixtures, conveyor belts, baskets, fans, furnace mufflers), nuclear power plants, chemical and petrochemical industries and heat exchangers.

In nickel-iron superalloy Inconel 718, ultranegrain and NS states allow the fabrication of components by superplastic deformation at higher strain. Components operating at elevated temperatures are subjected to heat treatment to have strengthening coherent disperse particles of second phase precipitated. Mechanical properties of NS Inconel 718 are reported elsewhere [20]. But the data on mechanical properties of NS Inconel 718 after heat treatment are missing, and that is why such results are important.

\subsection{Initial Microstructure of IN718}

Multiple isothermal forging (MIF) of bulk samples from investigated alloy carried out to various strains resulted in the formation of $\mathrm{MC}$ and NS states with mean grain sizes: $1 \mathrm{~mm}$ and $0.08 \mathrm{~mm}$ (figure7). The TEM and SEM [21] studies have shown that the duplex structure consists of g-phase and high temperature modification of 
$\mathrm{Ni3} \mathrm{Nb}-\delta$-phase. Plates of $\delta$-phase with non-coherent boundaries are distributed uniformly. The NS state is characterized by higher dislocation density and nonequilibrium $\gamma / \gamma$ boundaries [22]. Carbides with a mean size of $5 \mu \mathrm{m}$ are present.

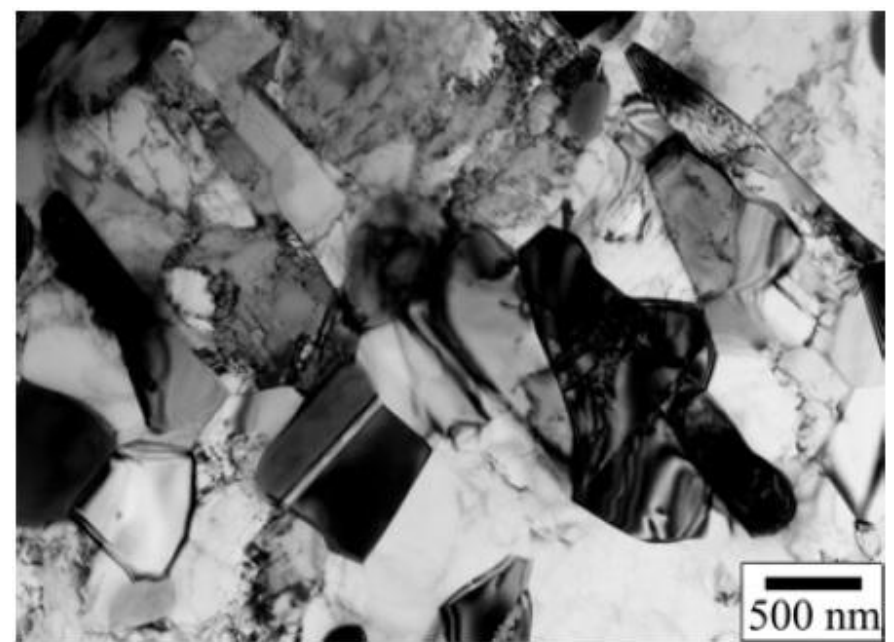

(a)

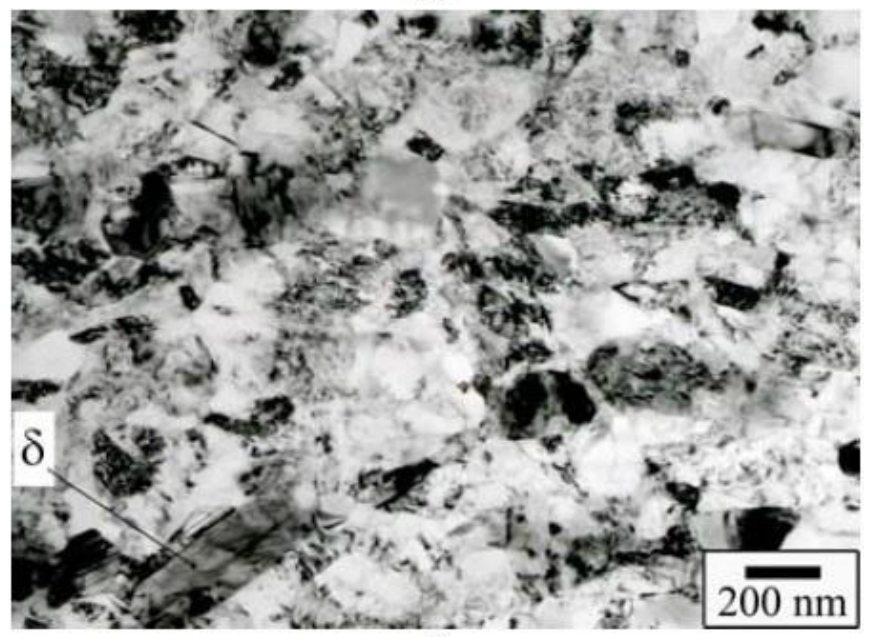

(b)

Figure 7: TEM image of Inconel 718 produced byMIF with mean grain size: (a)-1 $\mu \mathrm{m}$; (b)- $0.08 \mu \mathrm{m}$.

\subsection{Micrographs of Superalloys}

IN718 nickel-based superalloy is investigated in using reflected light microscope with Nomarski filter, and the material is held for 20 minutes, 6 hours, and 72 hours at $850^{\circ} \mathrm{C}$.In figure 8 , the micrograph shows that no precipitation has occurred $[23,24]$. It can be seen that small $y$ " precipitates have precipitated out within the matrix [25]. In figure 9, the volume fraction of $d$ is greater than when held for shorter periods of time. In figure 10 , the long precipitates are seen to have become more spheroidal than after shorter periods.

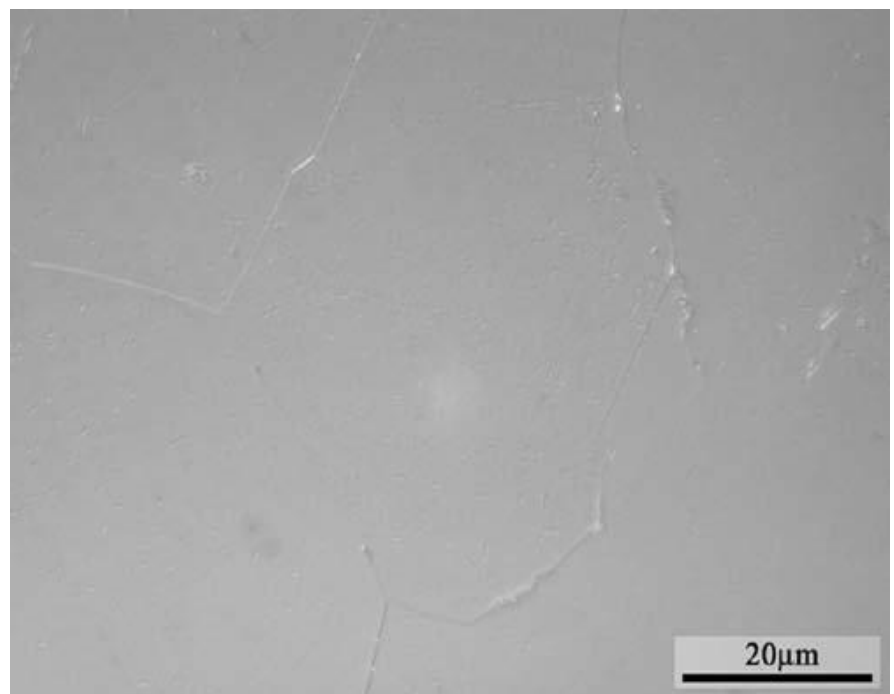

Figure 8: IN718 nickel-based superalloy held for 20 min at $850^{\circ} \mathrm{C}$.

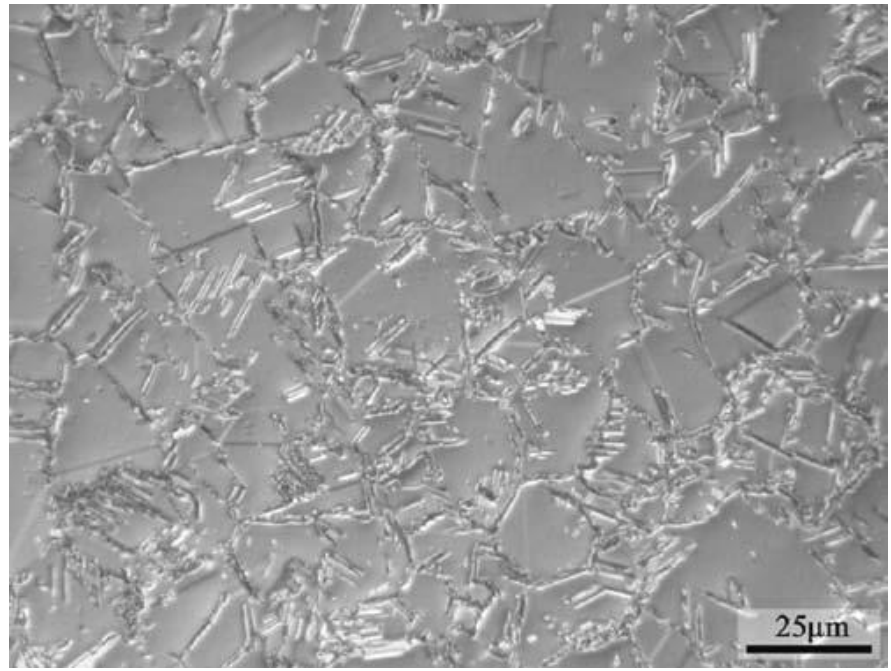

Figure 9: IN718 nickel-based superalloy held for $6 \mathrm{~h}$ at $850^{\circ} \mathrm{C}$.

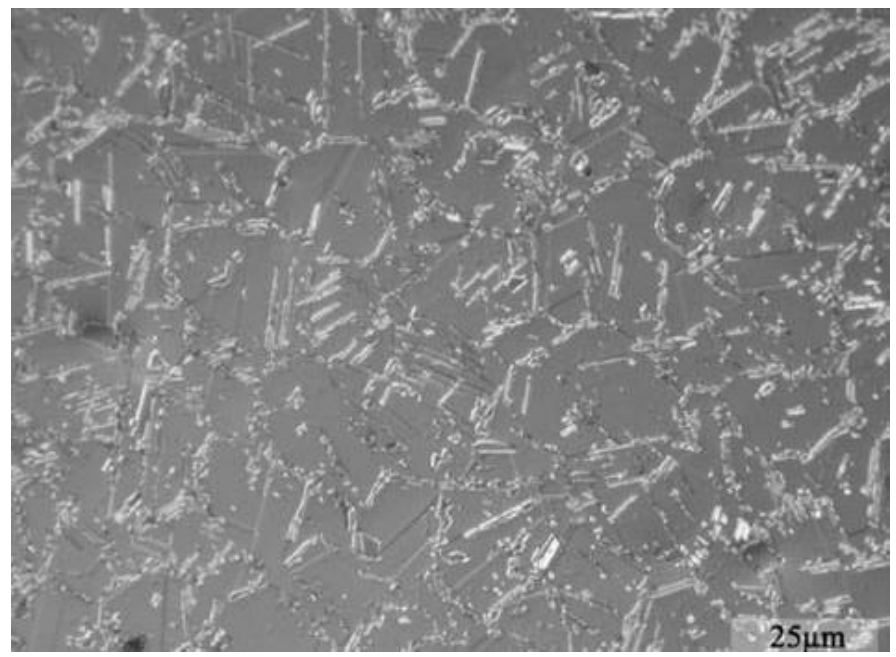

Figure 10:IN718 nickel-based superalloy held for $72 \mathrm{~h}$ at $850^{\circ} \mathrm{C}$. 


\subsection{Mechanical properties of alloy after MIF at room temperature}

According to the Hall-Petch relationship the strength of metals and alloys increases with decreasing grain size [26]. Tensile properties of Inconel 718 after MIF with various grain sizes are shown in table 3. The NS $(\gamma+\delta)$ alloy exhibits very high room temperature strength, which is much higher than that of the $\left(\gamma+\gamma^{\prime \prime}\right)$ alloy subjected to the strengthening thermal treatment. At the same time, increase in strength of this alloy in a NS state is accompanied by some reduction of ductility.

\begin{tabular}{llllll}
\hline $\begin{array}{l}\text { Grain size } \\
(\mu \mathrm{m})\end{array}$ & Phases & $\begin{array}{l}\text { Ultimate strength } \\
(\mathrm{MPa})\end{array}$ & $\begin{array}{l}\text { Yield strength } \\
(\mathrm{MPa})\end{array}$ & $\begin{array}{l}\text { El } \\
(\%)\end{array}$ & $\begin{array}{l}\text { RA } \\
(\%)\end{array}$ \\
\hline- & $\gamma+\gamma^{\prime \prime}$ & $\geq 1276^{\mathrm{a}}$ & $\geq 1034$ & $\geq 12$ & $\geq 15$ \\
$1^{\mathrm{b}}$ & $\gamma+\delta$ & 1184 & 920 & 21.9 & 22.2 \\
$0.3^{\mathrm{b}}$ & $\gamma+\delta$ & 1560 & 1300 & 5.1 & 11.0 \\
$0.08^{\mathrm{b}}$ & $\gamma+\delta$ & 1920 & 1845 & 4.8 & 6.1 \\
\hline
\end{tabular}

Table 3: Mechanical properties of alloys after MIF at room temperature.

The data on mechanical properties of the heat treated alloy are presented in table 4. These data evidently correspond to the material specification requirements. It is obvious that the initial nanostructure leads to maximum strength for the alloy at room temperature.

\subsection{Mechanical properties after heat treatment}

The studies on microstructure after carrying out the standard heat treatment [27] of MC and NS alloys showed that it resulted in the generation of uniform structure, the average grain sizes of g-phase being 3.9 and $4.6 \mu \mathrm{m}$, accordingly. The difference of initial structural states is inherited after carrying out thermal treatment. From figure 11 it is evident that after heat treatment (HT) some quantity of globular $\delta$-phase is present in grain boundaries, which retards grain growth during annealing. Volume fraction of $\delta$-phase is $2.9 \%$ for MC state after heat treatment and 3.3\% for NC state.

\begin{tabular}{|c|c|c|c|c|c|c|c|}
\hline \multirow[b]{2}{*}{ State } & \multirow{2}{*}{$\begin{array}{l}\text { Ultimate } \\
\text { strength } \\
\text { (MPa) }\end{array}$} & \multirow{2}{*}{$\begin{array}{l}\text { Yield } \\
\text { strength } \\
\text { (MPa) }\end{array}$} & \multirow{2}{*}{$\begin{array}{l}\text { El } \\
(\%)\end{array}$} & \multirow{2}{*}{$\begin{array}{l}\text { RA } \\
(\%)\end{array}$} & \multirow{2}{*}{$\begin{array}{l}\text { Grain } \\
\text { sizes } \\
(\mu \mathrm{m})\end{array}$} & \multicolumn{2}{|c|}{ Fatigue strength } \\
\hline & & & & & & (MPa) & (Cycles) \\
\hline AMS 5662 & $\geq 1276 / 1000^{b}$ & $\geq 1034 / 862$ & $\geq 12 / 12$ & $\geq 15 / 15$ & - & - & - \\
\hline $\mathrm{CG}+\mathrm{HT}^{\mathrm{a}}$ & $1428 / 1176$ & $1180 / 976$ & $19 / 18$ & $20 / 32$ & $11-22$ & 910 & $10^{5 c}$ \\
\hline $\mathrm{MC}+\mathrm{HT}$ & $1488 / 1169$ & $1234 / 995$ & $17 / 23$ & $23 / 45$ & 4.6 & 910 & $>1.6 \cdot 10^{\prime}$ \\
\hline $\mathrm{NS}+\mathrm{HT}$ & $1520 / 1164$ & $1252 / 993$ & $19 / 21$ & $35 / 42$ & 3.9 & 910 & $>1.6 \cdot 10^{:}$ \\
\hline
\end{tabular}

Table 4: Mechanical properties of Inconel 718 after MIF and heat treatment.

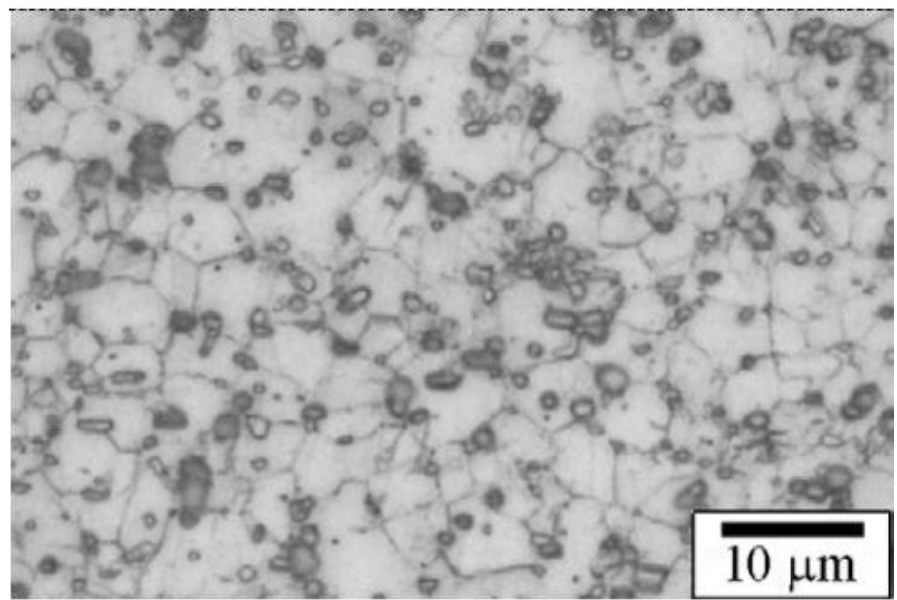

(a) $\_M C+H T$

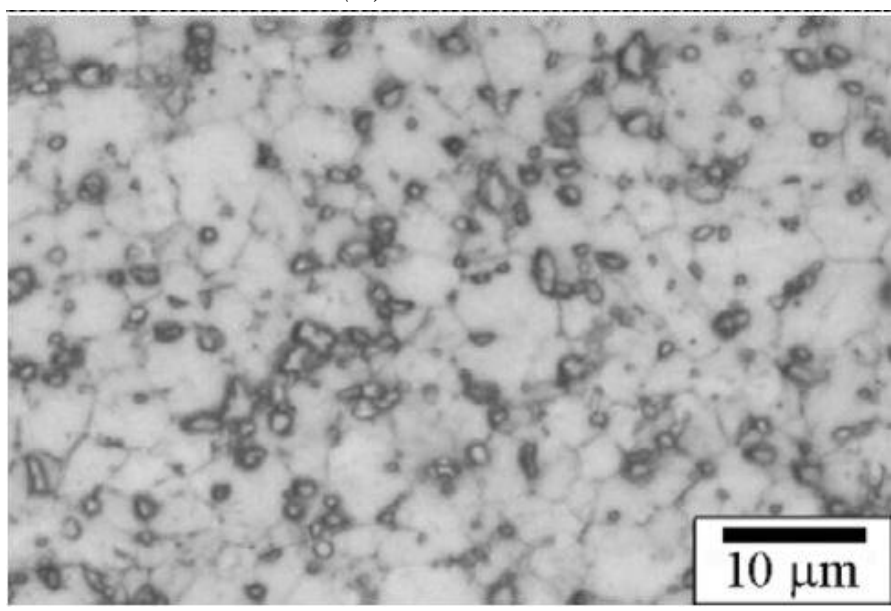

(b) $\_N S+H T$

Figure 11: Microstructure of Inconel 718 after MIF and heat treatment: $(a),(b)$

Comparative fatigue tests of the samples at room temperature have shown that the properties of NS alloy on the scale of $10^{5}$ cycles are higher by the factor of 1.6 than those stipulated elsewhere [28]. Stress rupture data shown in table 5 indicate that with decreasing a mean grain size of $\gamma$-phase one observes the tendency towards decrease of stress rupture and increase of ductility. All presented conditions meet the material specification requirements.

\begin{tabular}{ccccc}
\hline State & Stress (MPa) & Time (hrs) & El (\%) & RA (\%) \\
\hline AMS 5662 & 689 & $\geq 23$ & $\geq 4$ & - \\
\hline MC+HT & \multirow{2}{*}{710} & 29.8 & 20.2 & 61.0 \\
NS+HT & & 27.0 & 25.3 & 73.5 \\
\hline
\end{tabular}

Table 5: Stress rupture data at $650^{\circ} \mathrm{C}$ of Inconel 718after MIF and heat treatment.

The investigation results show that for increasing alloy's strength properties at operating temperaturesit are appropriate to have d-phase totally dissolved in order to increase the quantity of strengthening $\gamma$ "-phase precipitates during aging. 


\section{Conclusion}

A superalloy is a metallic alloy which is developed to resist most of all high temperatures, usually in cases until $70 \%$ of the absolute melting temperature. All of these alloys have an excellent creep, corrosion and oxidation resistance as well as a good surface stability and fatigue life.[29]

The main alloying elements are nickel, cobalt or nickel - iron, which can be found in the VIII. group of the periodic system of the elements. They are mostly used in aerospace and nuclear industry, e.g. engines. The development of these advanced alloys allows a better exploitation of engines, which work at high temperatures, because the Turbine Inlet Temperature (TIT) depends on the temperature capability of the material which forms the turbine blades. Nickel-based superalloys can be strengthened through solid-solution and precipitation hardening [30].

Nickel-based superalloys can be used for a higher fraction of melting temperature and are therefore more favorable than cobalt-based and iron-nickel-based superalloys at operating temperatures close to the melting temperature of the materials.

The newly investigated IN718 nickel-based superalloy which is the last version of Inconel 718 has been proceeding in the way to become a material that aerospace and defense industries never replace of any other material with combining its good mechanical properties, easy machinability and low cost.[31] With decreasing grain size to NS state of alloy 718 occurs a significant increase of strength properties at room temperature, in particular ultimate strength increased up to $1920 \mathrm{MPa}$. It is highly appropriate to employ NS Inconel 718 after heat treatment when it possesses high strength and sufficient ductility. For increasing service life of NS Inconel 718 components it is reasonable to develop a special heat treatment.

\section{References}

1. D. Locq, A. Walder, M. Marty, P. Caron," Development of New PM Superalloys for High Temperature Applications. EUROMAT, Intermetallics and Superalloys Vol. 10", WILEY-VCH Verlag Gmbh, Weinheim, Germany (D.G. Morris et al., eds), 2000.

2. Sims, C. T., Stoloff, N. S., and Hagel, W. C., "Superalloys II", Wiley, New York, 1986.
3. Betteridge, W., Heslop, J.,"The Nimonic Alloys, and Other Nickel-Base High-TempratureAlloys", New York, 1974.

4. Insg Secretariat Briefing Paper, "Nickel-Based Super Alloys", April 2013 - No.20.

5. Tresa M. Pollock, Sammy Tin, "Nickel-Based Superalloys for Advanced Turbine Engines: Chemistry, Microstructure, and Properties", University of Michigan, Ann Arbor, Michigan 48109, University of Cambridge, Cambridge, England CB2 3QZ, United Kingdom, 2006.

6. D. Locq, P. Caron,'On Some Advanced NickelBased Superalloys for Disk Applications", Journal Aerospace Lab, 2011.

7. Vedat Veli ÇAY, and Sermin OZAN ,"Superalloys and Application Areas", Doğu Anadolu Bölgesi Araştırmaları; 2005.

8. Hagel, W.C., Wiley, J., "The Superalloys", New York, 1972.

9. Milan T. Jovanović, Borislav Lukić, Zoran Mišković, Ilija Bobić, Ivana Cvijović, Biljana Dimčić, "Processing and Some Applications of Nickel, Cobalt and Titanium-Based Alloys", Association of Metallurgical Engineers of Serbia.

10. Melih Cemal Kushan, Sinem Cevik Uzgur, Yagiz Uzunonat and Fehmi Diltemiz, "ALLVAC 718 Plus $^{\mathrm{TM}}$ Superalloy for Aircraft Engine Applications", Eskisehir Osmangazi University ,Ondokuz Mayis University, Anadolu University Air Supply and Maintenance Base Turkey.

11. M. Gel\& D. N. Duhl and A. F. Giamei,"The Development of Single Crystal Superalloy Turbine Blades", Pratt \& Whitney Aircraft Group East Hartford, Connecticut 06108.

12. Mattingly, J.D.,"Elements of Gas Turbine Propulsion”, Mcgrawhill Co, 1996.

13. Nageswara Rao Muktinutalapati, "Materials for Gas Turbines - An Overview”, VIT University,India.

14. M.B. Henderson, D. Arrellb, M. Heobel, R. Larssonb and G. Marchantc," Nickel-Based Superalloy Welding Practices for Industrial Gas Turbine Applications".

15. Tien, J. K., and Caulfield, T., Superalloys, Supercomposites and Superceramics, Academic Press, New York, 1989.

16. ASM International All Rights Reserved, "Superalloys for High Temperatures", "Superalloys: A Technical Guide", 2002. 
17. Sims, C. T., Stoloff, N. S., and Hagel, W. C., Superalloys II, Wiley, New York, 1986.

18. Maurer, G. E., Castledine,W., Schweizer, F. A., and Mancuso, S., "Development of HIP Consolidated P/M Superalloys for Conventional Forging to Gas Turbine Components," Superalloys 1996, TMS, Warrendale, PA, 1996, pp. 645-652.

19. Wright, P. K., Jain, M., and Cameron, D., "High Cycle Fatigue in a Single Crystal Superalloy: Time Dependence at Elevated Temperature," Superalloys 2004, TMS, Warrendale, PA, 2004.

20. Mukhtarov Sh, Valitov V, Gigliotti M F X, Subramanian PR, Marte J S and Dudova N 2008 Mater. Sci. Forum 584-586 1 458-63

21. Mukhtarov Sh Kh 2010 Mater. Sci. Forum 633634 569-75 in press

22. Valitov V. A., Mukhtarov S. K. and Raskulova Y. A., "The Physics of Metals and Metallography", 2006.

23. Loria, E. A., "Superalloy 718: Metallurgy and Applications", TMS, Warrendale, PA, 1989.

24. Durand-Charre, M., "The Microstructure of Superalloys, Gordon and Breach", Amsterdam, 1997.

25. Guest, R., Rolls-Royce University Technology Centre, Department of Materials Science and Metallurgy, University of Cambridge, DolTPoMS Micrograph Library.

26. Valiyev R Z and Alexandrov I V 2000 Nanostructured Materials Processed by Severe Plastic Deformation (Moscow: Logos)

27. Chandler W T, Ghosh A K and Mahoney W M 1984 Superplastic forming and diffusion bonding of Inconel 718 J. Spacecraft $21161-4$

28. http://www.specialmetals.com/documents/Incone 1\%20alloy\%20718.pdf

29. Crompton, J. S., and Martin, J. W., "Crack Growth in a Single Crystal Superalloy at Elevated Temperature," Metallurgical Transactions A, Vol. 15A, 1984.

30. Larsen, J. M., and Christodoulou, "Using Materials Prognosis to Maximize the Utilization of Complex Mechanical Systems," Journal of Metals, Vol. 56, No. 3, 2004.

31. Karunarante, M. S. A., and Reed, R. C., "Interdiffusion of Platinum- Group Metals in Nickel at Elevated Temperatures," Acta Materialia, Vol. 51, No. 10, 2003. 